\title{
Science Academies' Refresher Course on Modern and Ancient Environment and Ecology: Sediments and Biota
}

\author{
at \\ Department of Geological Sciences, Jadavpur University, Kolkata \\ 4-24 December 2017 \\ Sponsored by \\ Indian Academy of Sciences, Bengaluru \\ Indian National Science Academy, New Delhi \\ The National Academy of Sciences, India, Allahabad
}

\begin{abstract}
A Refresher Course on Modern and Ancient Environment and Ecology will be held at Department of Geological Sciences, Jadavpur University, Kolkata, from 4-24 December 2017 for the benefit of faculty involved in teaching undergraduate and postgraduate courses. The Refresher course programme will be imparted in two parts: The first part will cover the theoretical aspects which will help to nurture the background of the participants for the field work. The theoretical and practical classes for one week (from 4-10 December,2017) will be held in the Department of Geological Sciences, Jadavpur University. The 2nd part of the programme (from 11-24 December,2017) is dedicated to Fieldwork along the coast of Bay of Bengal (Chandipur and the adjoining areas) and Baripada marine beds, Orissa. In this fieldwork the participants are expected to utilize their theoretical background for interpreting the geological products. This course is sponsored by the Indian Academy of Sciences, Bangalore, Indian National Science Academy, New Delhi and The National Academy of Sciences, India, Allahabad.
\end{abstract}

Refresher courses combining class teaching and field work, both in modern and ancient environment held so far have been highly successful. The fieldwork in the modern environment along the Orissa coast will help to understand the process - product relationship while the ancient Baripada marine beds will provide a scope to interpret the process from the products. The course will be directed by Prof. Pulak. Sengupta, AvH Fellow, F.A.Sc., F.N.A (pulaksg@gmail.com). It may be noted that UGC regulations include Refresher Courses in API scores for career advancement.

Applications are invited from teachers with experience in teaching undergraduate and postgraduate courses in Earth Science. Motivated research scholars may also apply. The number of seats will be about 30. Selected participants will be provided with travel assistance (limited to three-tier A/c train fare), accommodation and local hospitality during the Course in addition to course material.

Interested applicants must submit their application ONLINE by clicking on the following link http://web-japps.ias.ac.in: 8080/Refreshcourse/JRJR.jsp

A copy of the application form signed by the applicant should also be sent by Post to the Course Coordinator, at the address given below. In case of teachers, the form must also be signed and stamped by the Head of the applicant's Institution stating that leave will be sanctioned if the applicant is selected for the Course. A recommendation letter from a teacher is essential for Research Scholar applicants. Scanned copies of the duly signed documents sent by Email will also be accepted.

Address for communication: Prof. Subir Sarkar, Course Coordinator, Refresher Course on Modern and Ancient Environment and Ecology: Sediments and Biota; Department of Geological Sciences, Jadavpur University, Kolkata 700 032, Email: jugeoss@gmail.com, ssarkar@geology . jdvu . ac . in, Phone: +9133 24146366, (0)9432406174 (m).

Last date for the receipt of applications: 7 November 2017.

Selected participants will be informed on or before: 15 November 2017. 